\title{
Lysogenic Conversion of Rhizobium trifolii
}

\author{
By YVONNE M. BARNET AND J. M. VINCENT \\ School of Microbiology, University of New South Wales, \\ Kensington, New South Wales 2033, Australia
}

(Accepted for publication II February 1970)

\begin{abstract}
SUMMARY
Rhizobium trifolii strain SU 297, when lysogenized with phage 7 or its clearplaque mutant $7 \mathrm{cr}$, underwent lysogenic conversion that resulted in loss of ability to adsorb phages 7 and $7 \mathrm{cr}$ and the related phage 8 . The same conversion was reflected in changes in the surface of the bacterium by which a somatic antigen, characteristic of the parent strain, was modified and a new, noncrossreacting, antigen produced.
\end{abstract}

\section{INTRODUCTION}

The nature of their somatic antigens is one of several properties of bacteria that have been found to be subject to 'lysogenic conversion', i.e. modified as a result of the presence of a phage genome within the host. Almost all of these investigations have been concerned with the somatic antigens of Salmonella and have been comprehensively reviewed by Lüderitz, Staub \& Westphal (I966). One case involving a strain of Pseudomonas has also been reported (Holloway \& Cooper, 1962). The present paper arises from a further investigation of a defective lysogen (Rhizobium trifolii strain SU 298) which requires an inducing phage (phage $i_{s}$ ) liberated from $R$. trifolii strain SU 297, for the production of active phage (Takahashi \& Quadling, I96I; Barnet, 1969). In the course of this work it was found that $R$. trifolii strain SU 297 had its antigenic surface modified when it was lysogenized by phage 7 (one of two phages released by the induction of $R$. trifolii strain SU 298), or by phage $7 \mathrm{cr}$ (a clear-plaque mutant of phage 7 ).

\section{METHODS}

Bacteria and bacteriophage. Rhizobium trifolii strain sU 297/32 was used as a representative of the small-colony, non-gummy variant of SU 297 (Vincent, 1962). The lysogens of SU 297/32 have been designated SU 297(7) and SU 297(7cr), involving phages 7 and a clear-plaque mutant, $7 \mathrm{cr}$, respectively. Phage 7 was obtained by the induction of the defective lysogen ( $R$. trifolii strain SU 298) with phage $i_{s}$, and detected by means of plaque formation on SU 297. Phage 8, obtained similarly from SU 298, formed plaques on the strain from which it was derived (Takahashi \& Quadling, I96I). We have reverted to the original numbering of these hosts with which Marshall (1956) first demonstrated lysogenicity in the genus Rhizobium.

Media and cultivation. Phage broth, used for liquid culture and as the diluent for phage and bacterial dilutions, had the composition: $2.5 \mathrm{~g}$. sucrose; $0.5 \mathrm{~g}$. $\mathrm{K}_{2} \mathrm{HPO}_{4}$; 0.2 g. $\mathrm{MgSO}_{4} .7 \mathrm{H}_{2} \mathrm{O} ; 0 . \mathrm{I}$ g. $\mathrm{NaCl} ; 0.16$ g. $\mathrm{CaSO}_{4} ; 0.02$ g. $\mathrm{FeCl}_{3} ; 0.5$ g. Oxoid yeast 
extract; distilled water, I l. Mannitol nitrate agar, used for the poured plates for phage assay, contained: $0.45 \mathrm{~g}$. $\mathrm{Na}_{2} \mathrm{HPO}_{4} .12 \mathrm{H}_{2} \mathrm{O} ; 0.06 \mathrm{~g}$. $\mathrm{Na}_{2} \mathrm{SO}_{4} .10 \mathrm{H}_{2} \mathrm{O} ; 0.6 \mathrm{~g} . \mathrm{KNO}_{3}$; 0.01 g. $\mathrm{FeCl}_{3} ; 10.0$ g. mannitol; 0.06 g. $\mathrm{CaCl}_{2} ; 0.1 \mathrm{~g}$. $\mathrm{MgCl}_{2} .6 \mathrm{H}_{2} \mathrm{O} ; 100 \mu \mathrm{g}$. thiamine hydrochloride; $0.5 \mu \mathrm{g}$. biotin; $7.5 \mathrm{~g}$. Oxoid 'Ionagar'; distilled water, I l. The bacteria used as a source of antigens and for the absorption of agglutinins were grown in liquid mannitol nitrate medium. Incubation was carried out at $26^{\circ}$. Liquid cultures were grown in flasks shaken in a bath.

Adsorption of bacteriophage. The bacterial suspension was freed from observable clumps by centrifugation for $5 \mathrm{~min}$. at $1200 \mathrm{~g}$ and the supernatant standardized to contain between $250 \times 10^{6}$ and $500 \times 10^{6}$ bacteria/ml. The bacteriophage suspension was obtained by incubating the infected bacteria overnight in low salt broth $(0.25 \%$ sucrose, $0.05 \%$ Oxoid yeast extract) to avoid difficulties due to clumping and inhibition of liberated phage (Barnet, 1969). Residual bacteria were removed from the lysate by membrane filtration. Adsorption was carried out at $26^{\circ}$ and the reaction stopped at the required times by roo-fold dilution of the samples in ice-cold broth containing I0 \% (v/v) chloroform to kill the bacteria. Bacteria and adsorbed phage were removed by centrifugation and the residual titre of the supernatant determined in the usual way.

When using a lysogenic strain of SU 297/32 it was necessary to distinguish residual (unadsorbed) phage from the normal background count of phage produced spontaneously from the lysogen. When the added and resident phage were of different plaque types (phage 7 and $7 \mathrm{cr}$ ) the distinction could be made directly. Otherwise a control had to be set up to establish the background count due to spontaneous induction.

Serological methods. Antisera against whole or broken bacteria were produced in rabbits using a combination of intramuscular and intravenous injections (Humphrey \& Vincent, 1965). Quantitative absorption of agglutinins followed the method of Vincent \& Humphrey (1968). Whole cell antisera were diluted with saline $(0.85 \% \mathrm{NaCl})$ to give an initial standard agglutinating titre of 400 . The absorbing cells were grown for $72 \mathrm{hr}$ at $26^{\circ}$ in mannitol nitrate medium, sedimented, washed with distilled water and resuspended in saline to give an initial concentration of $300 \mu \mathrm{g}$. dry wt $/ \mathrm{ml}$. The required absorbing doses were then sedimented from appropriate volumes of the initial suspension, resuspended in antiserum diluted $\mathrm{I} / 25$, shaken for $\mathrm{I} \mathrm{hr}$ at $37^{\circ}$ and held at $4^{\circ}$ for $18 \mathrm{hr}$. The bacteria were then sedimented and the residual somatic agglutination titre of the supernatant determined with the strain of bacterium that had been used for developing the antiserum under test. Gel diffusion followed the detailed procedure of Humphrey \& Vincent (1965), based on that adapted for use with Rhizobium by Dudman (1964). Oxoid Ionagar no. $2(0.75 \%$ ) was used with $0.85 \% \mathrm{NaCl}$ and $0.25 \%$ sodium azide to give a layer $4 \mathrm{~mm}$. deep. Wells were $4 \mathrm{~mm}$. diameter and $8 \mathrm{~mm}$. apart. The test bacteria were sedimented, resuspended in saline, broken by shaking with ballotini beads on the Mickle disintegrator for 20 min. at $4^{\circ}$ and used as antigen against undiluted antisera. 


\section{RESULTS}

\section{Adsorption of phage}

Lysogenization of Rhizobium trifolii strain su $297 / 32$ with phage 7 prevented adsorption of phages $7,7 \mathrm{cr}$ and 8 (Fig. I $a$ to $c$ ). Similarly, lysogenization with phage $7 \mathrm{cr}$ prevented the uptake of phage 7 (Fig. I $d$ ). These results with the two independently developed, though related, lysogens indicate that lysogenization was indeed responsible for the alteration of the receptor sites of the parent bacterium.
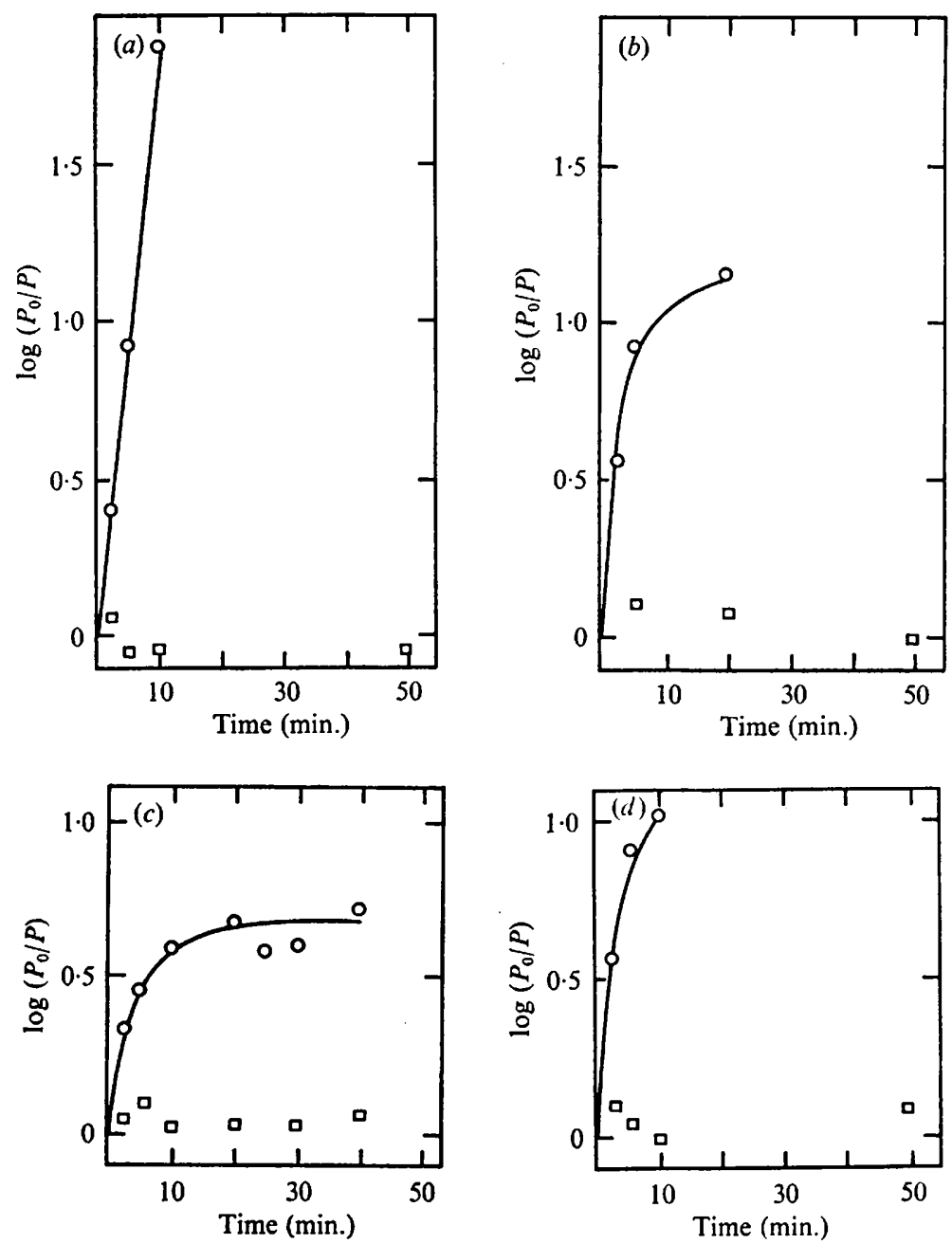

Fig. 1. Effect of lysogenization on the adsorption of phage $7(a)$, phage $7 \operatorname{cr}(b)$ and phage $8(c)$ to Rhizobium trifolii strain su 297/32 (O), and strain su 297(7) ( $\square)$. In (d), phage 7 adsorbed to strain SU 297/32 (O) and strain sU 297(7cr) ( $\square$ ). $P_{0}$ phage titre at commencement, $P=$ phage titre after $t$ min. 


\section{Surface antigens}

It seemed likely that changes in receptor sites would be accompanied by changes in the surface antigens of the bacterium. This was tested by the technique of quantitative absorption of agglutinins and by gel diffusion. Figure 2 shows the reciprocal quantitative absorption test with the two kinds of bacteria and their antisera. From Fig. $2 a$ (antiserum for non-lysogenized strain SU 297/32) it can be concluded that the lysogenized culture had sufficient of the same, or similar, antigen as the non-lysogenized to remove virtually all of agglutinins when used in a sufficiently large absorbing dose ( $>480 \mu \mathrm{g}$.) $\mathrm{ml}$.). However, the nature of the homologous and non-homologous curves in the range of less concentrated absorbing dose shows that in strain SU 297(7) the responsible antigen after lysogenization is either qualitatively different or less concentrated than in the parent strain.

(a)

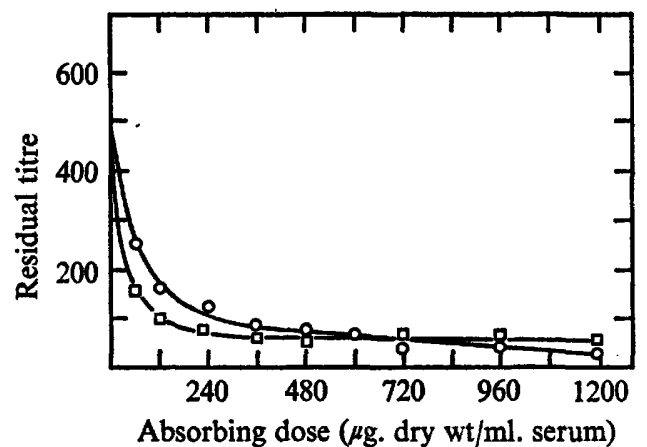

(b)

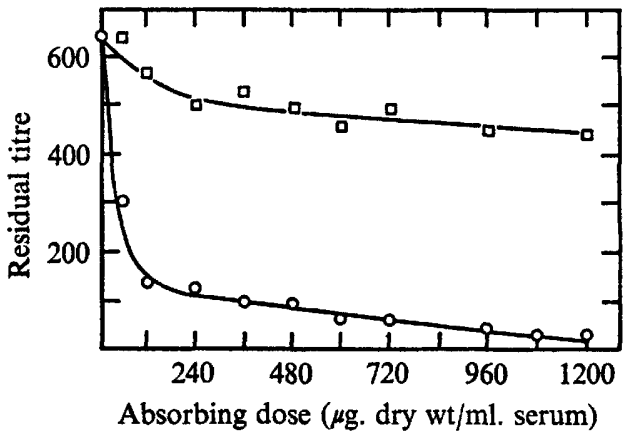

Fig. 2. Absorption of antiserum to Rhizobium trifolii strain sU 297/32 (a) or strain SU 297(7) (b), with $R$. trifolii su 297/32 ( $\square$ ) and sU $297(7)(O)$.

The difference in the reciprocal test (using antiserum prepared against the lysogenic strain sU 297(7); Fig. 2b) is more striking. The non-lysogenized strain (sU 297/32) left a large amount of antibody unabsorbed. showing that lysogenization had resulted in the appearance of at least one new antigenic determinant. In addition, the common antibody was removed less efficiently. If the difference in the homologous and nonhomologous curves of Fig. $2 a$ had resulted from quantitative differences in a common antigen, the non-lysogenic strain SU 297/32 should have remained the more efficient absorbent in this reciprocal experiment. The results therefore support a qualitative difference in the cross-reacting antigens of lysogenized and non-lysogenized strains.

\section{Diffusing antigens}

Gel diffusion between broken rhizobia as antigen and the corresponding antisera yield precipitation lines that have been identified (Humphrey \& Vincent, 1965) with somatic antigens (' $a$ ' lines nearest the antigen well) and internal antigens (' $b$ ' and ' $c$ '). This technique was applied to obtain more information about changes in antigenic properties caused by lysogenization. Figure 3 shows the ' $a$ ' line patterns obtained with graded amounts of non-lysogenized and lysogenized bacteria against the antisera to each. The ' $b$ ' and ' $c$ ' lines were unaffected and have been omitted to simplify the diagram. 
It can be concluded from the continuity of the line at higher antigen concentrations in Fig. $3 a$ that the lysogenized strain carried a similar somatic antigen to that of the non-lysogenized parent. However, the failure of the line to appear at lower concentrations (20 and $5 \mathrm{mg} . / \mathrm{ml}$. ), like the agglutinin absorption evidence, indicated that this antigen was either less concentrated in the lysogenized culture or had less affinity for antibodies formed against the normal strain. Spur formation in the reciprocal test (Fig. $3 b$ ) supported evidence from quantitative absorption that lysogenization had led to the production of a new antigenic group. This conclusion was substantiated by the diffusion pattern of Fig. 4, in which the diagonal line reflected an antigen unique to the lysogenized strain.

(a)

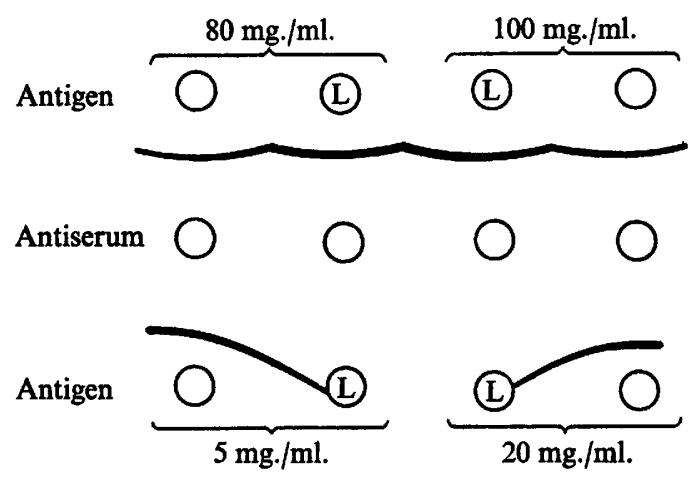

(b)

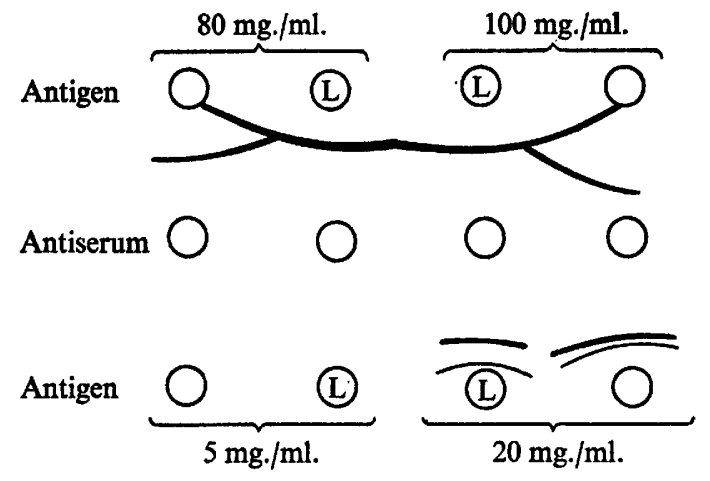

Fig. 3. Schematic representation of gel-diffusion patterns using antigenic material from Rhizobium trifolii strain sU 297/32 and strain SU 297(7) and antiserum against (a) R. trifolii strain SU 297/32 and (b) SU 297(7). Broken cells were suspended in saline to the concentrations shown (dry wt/ml.). Wells shown as open circles; those containing material from lysogenic bacteria (su 297(7)) labelled L.

\section{DISCUSSION}

Phage 7 released from Rhizobium trifolii strain SU 298 after exposure to phage $i_{s}$, for which strain SU 297 is already lysogenic, is probably the result of the formation of a genetic recombinant between defective prophage carried in SU 298 and phage $i_{\text {s }}$ (Barnet, 1969). The fact that phage 7 adsorbs normally on both SU 298 and normal SU 297 shows that neither the prophage precursor to phage 7 (carried by su 298) nor 


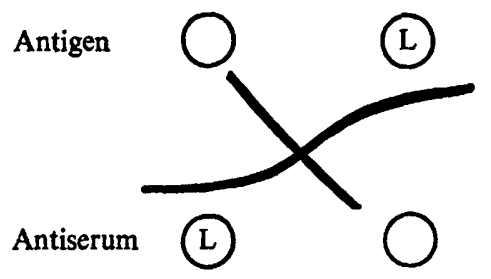

Fig. 4. Schematic representation of gel diffusion patterns obtained with broken cells of Rhizobium trifolii strain su297/32 and strain su 297(7) (100 mg. dry wt $/ \mathrm{ml}$.) diffused against antisera to su $297 / 32$ and sU 297(7). Wells shown as open circles. $\mathrm{L}=$ wells concontaining antigenic material from or antiserum against lysogenic bacteria (su 297(7)).

phage $i_{s}$ (for which SU 297 is already lysogenic) is able to cause this modification of the surface of these strains. It is possible that genes necessary for such surface modification are in fact present in the prophage of su 298 but are not expressed in that host. On the other hand, genetic information might have to be provided by both prophages, as could operate in SU 297 lysogenized by phage 7 . The first situation is found in the results of Uetake, Nakagawa \& Akiba (1955) and LeMinor, Ackermann \& Nicolle (1963); the second in those of Uetake \& Hagiwara (196I), who reported that two prophages $\left(\epsilon^{15}\right.$ and $\left.\epsilon^{34}\right)$ were needed in Salmonella anatum before antigen 34 was synthesized.

The parallel loss of phage-adsorbing capacity and the change in surface antigen found with lysogenized SU 297 suggests that the receptor site for phages $7,7 \mathrm{cr}$ and 8 is associated with the lipopolysaccharide somatic antigen of these bacteria (Humphrey \& Vincent, 1969). Receptor sites for several $T$ phages and Shigella phages have been found in the lipopolysaccharide surface layer (Jesaitis \& Goebel, 1955; Beumer, Beumer-Jochans, Dirkx \& Dekeil, I966) and some earlier work with rhizobial phages showed a relationship between antigenic constitution and susceptibility to specific phages (Marshall \& Vincent, 1954).

Modification of the phage sensitivity of cells by lysogenic conversion of the phage receptors has already been reported, for example in a group $E_{1}$ strain of Salmonella, after infection with phage $\epsilon^{15}$ and subsequently with phage $\epsilon^{34}$ (Uetake, Luria \& Burrows, 1958). As pointed out by Neubauer (1967), such conversions may provide a safeguard, additional to that of cytoplasmic immunity in lysogenic cells, preventing lysis by superinfecting virulent mutants of the homologous phage. Phage maintained in such protected lysogenic cells would have advantage in survival. Conversion of the immune lysogenic cell to a non-adsorbing form would also increase the efficiency of phage multiplication by preventing wasteful abortive infections.

We are indebted to Mrs B. A. Humphrey of this Department for advice on the techniques of quantitative absorption and gel diffusion, and for helpful discussion as to their interpretation. One of us (Y.M.B.) carried out this work as Commonwealth Post-graduate Scholar. 


\section{REFERENCES}

Barnet, Y. M. (1969). Bacteriophage of Rhizobium. Ph.D. Thesis. University of New South Wales.

Beumer, J., Beumer-Jochans, M. P., Dirkx, J. \& Dekeil, D. (I966). Localisation des récepteurs de phages chez des souches de Shigella et d'Escherichia. Annales de l'Institut Pasteur, Paris r1o, 727-736.

Dudman, W. F. (1964). Immune diffusion analysis of the extracellular soluble antigens of two strains of Rhizobium meliloti. Journal of Bacteriology 88, 782-794.

Holloway, B. W. \& Cooper, G. N. (1962). Lysogenic conversion in Pseudomonas aeruginosa. Journal of Bacteriology 84, $132 \mathrm{I}-\mathrm{I} 324$.

Humphrey, B. A. \& VINCENT, J. M. (1965). The effect of calcium nutrition on the production of diffusible antigens by Rhizobium trifolii. Journal of General Microbiology 41, I09-1 18.

HUMPHREY, B. A. \& VINCENT, J. M. (1969). The somatic antigens of two strains of Rhizobium trifolii. Journal of General Microbiology 59, $4 \mathrm{I}$ I-425.

Jesaitis, M. A. \& GoebeL, W. F. (I955). Lysis of T4 phage by the specific lipocarbohydrate of phase II Shigella sonnei. Journal of Experimental Medicine 102, 733-752.

LeMinor, L., Ackermann, H. W. \& Nicolle, P. (1963). Aquisition simultanée des facteurs or et 037 par des Salmonella du group G sous l'effet de la lysogenization (conversion antigénique). Annales de l'Institut Pasteur, Paris ro4, 469-476.

Lüderitz, O., STAUB, A. M. \& WestPhal, O. (I966). Immunochemistry of $O$ and $R$ antigens of Salmonella and related Enterobacteriaceae. Bacteriological Reviews 30, 192-255.

Marshall, K. C. (1956). A lysogenic strain of Rhizobium trifolii. Nature, London 177, 92.

Marshall, K. C. \& Vincent, J. M. (1954). Relationship between the somatic antigens of Rhizobium trifolii and susceptibility to bacteriophage. Australian Journal of Science 17, 68-69.

Neubauer, Z. (1967). Brief consideration of the meaning of the lysogenic conversion in Salmonella anatum phage systems. Nature, London 213, 1263.

TAKAHASHI, I. \& QUADLING, C. (I96I). Lysogeny in Rhizobium trifolii. Canadian Journal of Microbio$\log y 7,455-465$.

Uetake, H. \& Hagiwara, S. (196I). Genetic co-operation between unrelated phages. Virology 13, 500-506.

Uetake, H., Luria, S. E. \& Burrows, J. W. (1958). Conversion of somatic antigens in Salmonella by phage infection leading to lysis or lysogeny. Virology $5,68-9 \mathrm{I}$.

Uetake, H., NAKAGaWA, T. \& AKIBA, T. (I955). The relationship of bacteriophage to antigenic changes in Group E salmonellas. Journal of Bacteriology 69, 57I-579.

VinCENT, J. M. (1962). Australian studies of the root-nodule bacteria. A review. Proceedings of the Linnean Society of New South Wales 87, 8-38.

VINCENT, J. M. \& HUMPHREY, B. A. (I968). Modification of the antigenic surface of Rhizobium trifolii by a deficiency of calcium. Journal of General Microbiology 54, 397-405. 